\title{
Addressing bystander exposure to agricultural pesticides in life cycle impact
} assessment

Ryberg, Morten Walbech; Rosenbaum, Ralph K.; Mosqueron, Luc; Fantke, Peter

Published in:

Chemosphere

Link to article, DOI:

10.1016/j.chemosphere.2018.01.088

Publication date:

2018

Document Version

Peer reviewed version

Link back to DTU Orbit

Citation (APA):

Ryberg, M. W., Rosenbaum, R. K., Mosqueron, L., \& Fantke, P. (2018). Addressing bystander exposure to agricultural pesticides in life cycle impact assessment. Chemosphere, 197, 541-549.

https://doi.org/10.1016/j.chemosphere.2018.01.088

\section{General rights}

Copyright and moral rights for the publications made accessible in the public portal are retained by the authors and/or other copyright owners and it is a condition of accessing publications that users recognise and abide by the legal requirements associated with these rights.

- Users may download and print one copy of any publication from the public portal for the purpose of private study or research.

- You may not further distribute the material or use it for any profit-making activity or commercial gain

- You may freely distribute the URL identifying the publication in the public portal 


\title{
Addressing bystander exposure to agricultural pesticides in
}

\section{life cycle impact assessment}

\author{
Morten Walbech Ryberg $^{\mathrm{a} *}$, Ralph K. Rosenbaum ${ }^{\mathrm{b}}$, Luc Mosqueron ${ }^{\mathrm{c}}$, Peter Fantke ${ }^{\mathrm{a}}$
}

${ }^{a}$ Quantitative Sustainability Assessment Division, Department of Management Engineering, Technical University of Denmark, Bygningstorvet 116, 2800 Kgs. Lyngby, Denmark

${ }^{\mathrm{b}}$ ITAP, Irstea, Montpellier SupAgro, Univ Montpellier, ELSA Research group and ELSA-PACT Industrial Chair, 361 rue Jean-François Breton, BP 5095, F-34196 Montpellier Cedex 5, France

${ }^{\mathrm{c}}$ Veolia Environmental Research and Innovation, Departement of Environment and Santé, Chemin de la Digue, 78600 Maisons-Laffitte, France

*Corresponding author: E-mail address: moryb@dtu.dk, Phone: (+45) 45251636

\begin{abstract}
Residents living near agricultural fields may be exposed to pesticides drifting from the fields after application to different field crops. To address this currently missing exposure pathway in life cycle assessment (LCA), we developed a modelling framework for quantifying exposure of bystanders to pesticide spray drift from agricultural fields. Our framework consists of three parts addressing: (1) loss of pesticides from an agricultural field via spray drift; (2) environmental fate of pesticide in air outside of the treated field; and (3) exposure of bystanders to pesticides via inhalation. A comparison with measured data in a case study on pesticides applied to potato fields shows that our model gives good predictions of pesticide air concentrations. We compared our
\end{abstract}


Ryberg MW, Mosqueron L, Rosenbaum RK, Fantke P (2018) Addressing bystander exposure to agricultural pesticides in life cycle impact assessment. Chemosphere 197C:541-549. doi:

10.1016/j.chemosphere.2018.01.088

bystander exposure estimates with pathways currently included in LCA, namely aggregated inhalation and ingestion exposure mediated via the environment for the general population, and general population exposure via ingestion of pesticide residues in consumed food crops. The results show that exposure of bystanders is limited relative to total population exposure from ingestion of pesticide residues in crops, but that the exposure magnitude of individual bystanders can be substantially larger than the exposure of populations not living in the proximity to agricultural fields. Our framework for assessing bystander exposure to pesticide applications closes a relevant gap in the exposure assessment included in LCA for agricultural pesticides. This inclusion aids decision-making based on LCA as previously restricted knowledge about exposure of bystanders can now be taken into account.

Keywords: residential bystanders; pesticide emissions; near-field exposure; life cycle assessment; spray drift 
Ryberg MW, Mosqueron L, Rosenbaum RK, Fantke P (2018) Addressing bystander exposure to agricultural pesticides in life cycle impact assessment. Chemosphere 197C:541-549. doi:

10.1016/j.chemosphere.2018.01.088

\section{Introduction}

Residents living within short distance of agricultural fields may be exposed to spray drift emissions from pesticides designed to target field pests and weeds, during and after applications (Matthews and Hamey, 2003). Methods for estimating spray drift and potentially related exposure of residential bystanders have been proposed based on either empirical measurements (Ganzelmeier et al., 1995; Holterman and van de Zande, 2003; Kasiotis et al., 2014; Rautmann et al., 2001; Salyani and Cromwell, 1992; van de Zande et al., 2010) or mechanistic models (Arya, 2003; Craig, 2004; Kennedy et al., 2012; Lebeau et al., 2011; Miller and Hadfield, 1989; Reiss and Griffin, 2006; Teske et al., 1993, 2002). A detailed overview of identified spray drift models is provided in Section S-5 of the Supplementary material. These models are usually applied to support environmental risk assessment (ERA), while estimating pesticide exposure associated with spray drift fractions for bystanders living near agricultural fields is currently not included when comparing agricultural practices in a life cycle assessment (LCA) context (Rosenbaum et al., 2015). This is mainly due to the fact that while most of the existing modeling approaches are suitable for quantifying drift-related deposition profiles, their specific environmental and boundary conditions and underlying assumptions are usually not appropriate for assessing residential bystander exposure in an LCA context. LCA requires considering the number of residential bystanders in a defined area that are exposed to the integrated drift-related pesticide emission amount reaching that area from a pesticide application to the total agricultural field. Such a modeling approach, however, is currently not available for LCA. Hence, the potential contribution of exposure associated with spray drift fractions to overall population exposure and related impacts on human health relative to other exposure pathways including exposure to crop residues (Fantke et al., 2012a; Fantke and Jolliet, 2016) is currently unknown. This may lead to uninformed decisions and in some cases shift burden from population far-field or crop residue exposure to exposure of bystanders. 
Ryberg MW, Mosqueron L, Rosenbaum RK, Fantke P (2018) Addressing bystander exposure to agricultural pesticides in life cycle impact assessment. Chemosphere 197C:541-549. doi:

10.1016/j.chemosphere.2018.01.088

To address this issue, we aim in the present study to develop and apply a framework for quantifying exposure of bystanders to pesticide spray drift fractions from agricultural fields for integration in life cycle impact assessment (LCIA), and focus on the following specific objectives: (1) to propose a modeling framework for estimating bystander inhalation exposure to agricultural pesticides from spray drift, (2) to evaluate the model in terms of uncertainty using Monte Carlo simulation and in terms of comparing modeled air concentrations with field measurements in a case study of pesticides applied to potato fields, and (3) to compare the magnitude of estimated bystander exposure with overall population exposure to environmental far-field emissions (via fractions lost to the environment during and after pesticide application) and population exposure to residues in food crops. The results of this study close a known gap in exposure modelling in LCIA toxicity characterization by providing a quantitative estimate of inhalation exposure of bystanders to agricultural pesticides.

\section{Materials and Methods}

\subsection{Model framework}

We propose a model to estimate inhalation exposure of bystanders living in the vicinity of agricultural fields to the integrated air-borne pesticide spray fraction drifting beyond the field boundaries during and after application for inclusion as complementary exposure pathway in LCIA human toxicity characterization. A conceptual overview of the model setup is presented in Figure 1. In the following, we provide an overall description of the modeling framework, while further details of the approach and underlying model equations can be found in Section S-1 of the Supplementary material. 
Ryberg MW, Mosqueron L, Rosenbaum RK, Fantke P (2018) Addressing bystander exposure to agricultural pesticides in life cycle impact assessment. Chemosphere 197C:541-549. doi:

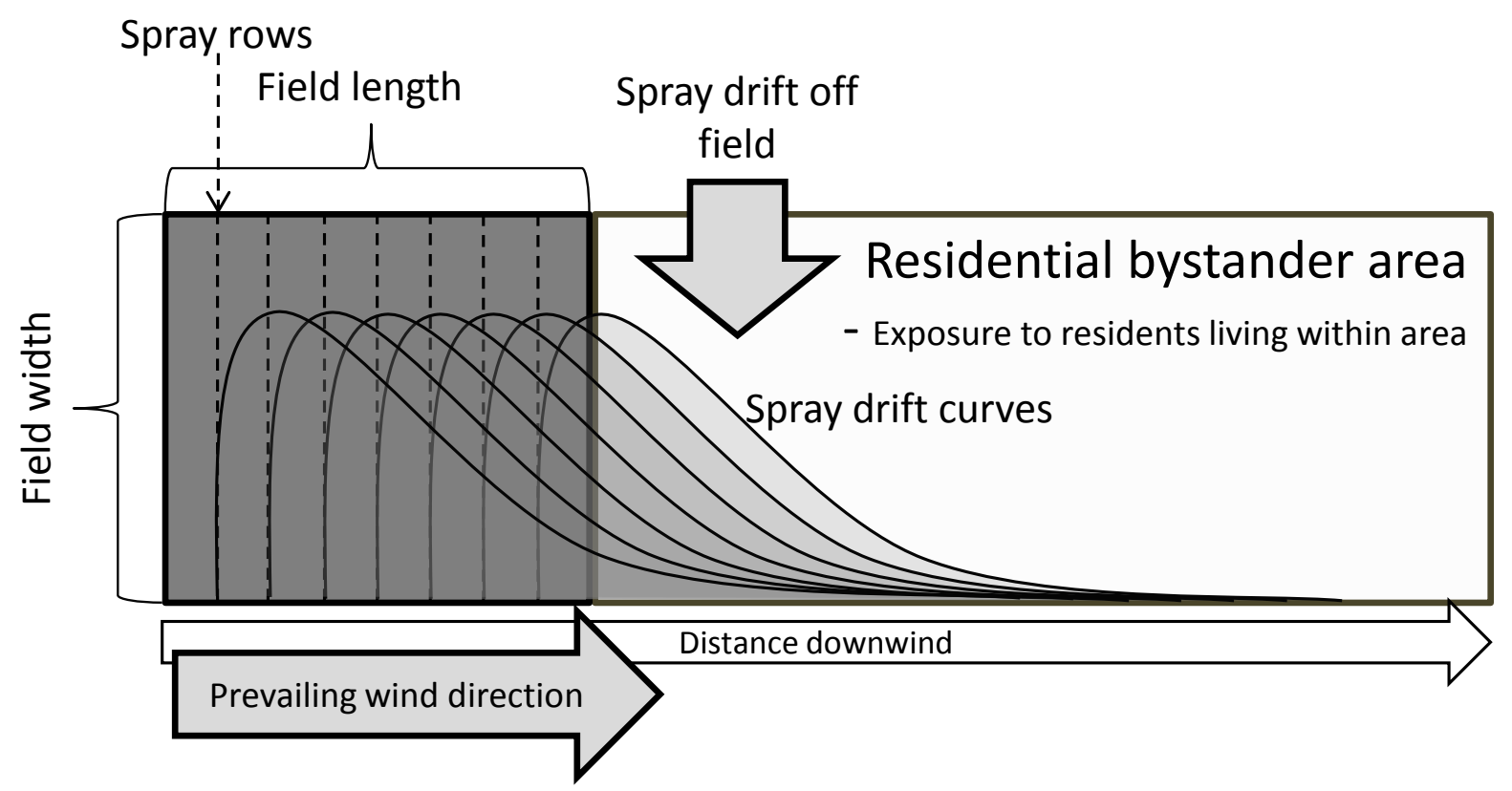

Figure 1 Conceptual overview of the approach to model pesticide spray drift from a field, and the model boundaries, where subsequent exposure to the integrated spray drift fraction over the considered residential bystander area is included. Off-field spray drift is inversely correlated with the distance between the sprayed field row and the field edge.

The residential bystander exposure model consists of three main parts: (1) the loss of pesticide from the agricultural field via spray drift after application; (2) environmental fate of the pesticides in air outside of the treated field; and (3) exposure of the bystander population to the pesticide spray drift fraction. Spray drift loss and environmental fate processes are considered by the fate factor, FF $\left[\mathrm{kg}_{\text {in air }}\right.$ per $\mathrm{kg}_{\text {applied }} \mathrm{d}^{-1}$ ], while human exposure is represented by the exposure factor, XF [ $\mathrm{kg}_{\text {inhaled }} \mathrm{d}^{-1}$ per $\mathrm{kg}_{\text {in air }}$ ], integrated over the boundaries of the considered bystander residence area. The human intake fraction $\mathrm{iF}\left[\mathrm{kg}_{\text {inhaled }} \mathrm{kg}_{\text {applied }}^{-1}\right]$ is a representative metric to express the mass of pesticide inhaled by the entire bystander population per unit of mass applied pesticide and can be calculated as the product of fate and exposure, i.e. FF $\times$ XF. The iF can then be multiplied with a human toxicity-related effect factor, EF [disease cases $\mathrm{kg}_{\text {inhaled }}^{-1}$ ] that relates 
Ryberg MW, Mosqueron L, Rosenbaum RK, Fantke P (2018) Addressing bystander exposure to agricultural pesticides in life cycle impact assessment. Chemosphere 197C:541-549. doi:

10.1016/j.chemosphere.2018.01.088

human inhalation intake to disease risk (Crettaz et al., 2002; Jolliet et al., 2006) to finally arrive at a characterization factor, CF [disease cases $\mathrm{kg}_{\text {applied }}^{-1}$ ], expressing the potential impacts on human health of bystanders from agricultural pesticide applications:

$\mathrm{CF}=\mathrm{FF} \times \mathrm{XF} \times \mathrm{EF}=\mathrm{iF} \times \mathrm{EF}$

Eq. 1

The residential bystander model estimates the exposure of residential and non-residential bystanders from initial spray drift. Exposure associated with continuous processes, such as volatilization and subsequent inhalation or deposition onto field crops and subsequent ingestion of crop residues, are not considered in the presented model, as the contribution of these pathways to overall population exposure is already considered by existing LCIA models, such as USEtox (Rosenbaum et al., 2008) and dynamiCROP (Fantke et al., 2011a, 2011b).

\subsubsection{Environmental fate of pesticides applied to fields}

The fate of the pesticides as expressed by the FF was estimated according to:

$$
\mathrm{FF}=\frac{m_{\text {in air }}}{\dot{m}_{\text {applied }}}=\frac{\sum_{i} m_{\text {in air }, i}}{\sum_{i} \dot{m}_{\text {applied }, i}}
$$

where $m_{\text {in air }, i}\left[\mathrm{~kg}_{\text {in air }}\right]$ is the time-integrated mass in air associated with spray row $i$, and $\dot{m}_{\text {applied, } i}$ $\left[\mathrm{kg}_{\text {applied }} \mathrm{d}^{-1}\right]$ is the mass applied per day to spray row $i$. The mass found in air is essentially a function of two components (see Supplementary material, Eq. S6) in line with recommendations based on a broad agreement regarding the modeling of the delineation of pesticide environmental distribution processes between life cycle inventory (LCI) and LCIA (Rosenbaum et al., 2015). The first component is considered in the LCI phase estimating the fraction of the pesticide applied to the field that is lost via spray drift, while the second component is considered in the LCIA phase estimating the fate of pesticides in air outside of the treated field. 
Ryberg MW, Mosqueron L, Rosenbaum RK, Fantke P (2018) Addressing bystander exposure to agricultural pesticides in life cycle impact assessment. Chemosphere 197C:541-549. doi:

10.1016/j.chemosphere.2018.01.088

Losses of pesticides from agricultural fields have been extensively assessed, where focus has primarily been on the deposition of the pesticides (Ganzelmeier et al., 1995; Holterman and van de Zande, 2003; Teske et al., 2002). Based on these studies, we calculated spray drift as a fraction of the applied pesticide mass separately for each nozzle row $i$ according to available drift deposition curves by e.g. Holterman and van de Zande (2003), which estimate the deposited fraction as a function of distance from the application site. At sufficiently large distance from the place of application, the entire fraction drifted from the field was assumed deposited. The deposition curves do not include the spray drift fraction that remains airborne, thus, slightly underestimating the total losses from the field. Nevertheless, this method was regarded as a good proxy for the total loss via spray drift. Based on this assumption, we estimated the applied pesticide fraction lost via wind drift using an emission quantification model building on PestLCI 2.0 (Dijkman et al., 2012), which we adapted to account for integrated emission mass beyond agricultural fields, buffer zones and drift curves applicable for potato cultivation:

$$
f r_{\mathrm{drift}, i}=\frac{1}{100} \times\left[\frac{\alpha_{1}}{\beta_{1}}\left(e^{-z_{1, i} \times \beta_{1}}-e^{-z_{2, i} \times \beta_{1}}\right)+\frac{\alpha_{2}}{\beta_{2}}\left(e^{-z_{1, i} \times \beta_{2}}-e^{-z_{2, i} \times \beta_{2}}\right)\right]
$$

where $f r_{\text {drift,i }}\left[\mathrm{kg}_{\text {drift }} \mathrm{kg}_{\text {applied }}^{-1}\right]$ is the fraction of pesticide lost from the field via spray drift and reaching the exposed area per mass applied in nozzle row $i \in\{1, \ldots, n\}, z_{1, i}[\mathrm{~m}]$ is the distance of spray row $i$ to the field edge, $z_{2, i}[\mathrm{~m}]$ is the distance of spray row $i$ to field edge plus $10,000 \mathrm{~m}$ after which all spray drift is assumed to be deposited, and $\alpha_{1}, \alpha_{2}, \beta_{1}, \beta_{2}$ are regression coefficients, which primarily depend on crop type, nozzle type and application technique (Holterman and van de Zande, 2003). The implemented drift deposition curves are based on spray drift of pesticides in aqueous formulations, for which our model is valid. Implementation of other spray drift curves (e.g. from Ganzelmeier et al., 1995; Kasiotis et al., 2014; Rautmann et al., 2001) is possible by adapting the integrated function in Eq. 3 to be based on the equation specific to any new spray drift curve. 
Ryberg MW, Mosqueron L, Rosenbaum RK, Fantke P (2018) Addressing bystander exposure to agricultural pesticides in life cycle impact assessment. Chemosphere 197C:541-549. doi:

10.1016/j.chemosphere.2018.01.088

Drift curves for similar crops and similar application techniques were found to vary substantially between studies. For instance, the total drift-related loss of pesticide from a single spray row expressed as \% of applied mass to potato crops using conventional ground boom sprayers was found to range from $15 \%$ to $73 \%$ depending on the spray drift curves used (see Supplementary material, Table S10). This variation is likely a result of differences in spray technologies used in the underlying spray drift studies, in environmental conditions during measurements, and in measurement setups and technologies.

For pesticide emissions beyond agricultural fields from each nozzle row $i$, the mass fraction of pesticides in the air was estimated as a function of distance based on a Gaussian plume dispersion model including terms for advection, horizontal and vertical dispersion processes yielding a time-integrated estimate of the average air mass fraction in the exposed bystander area as a function of distance:

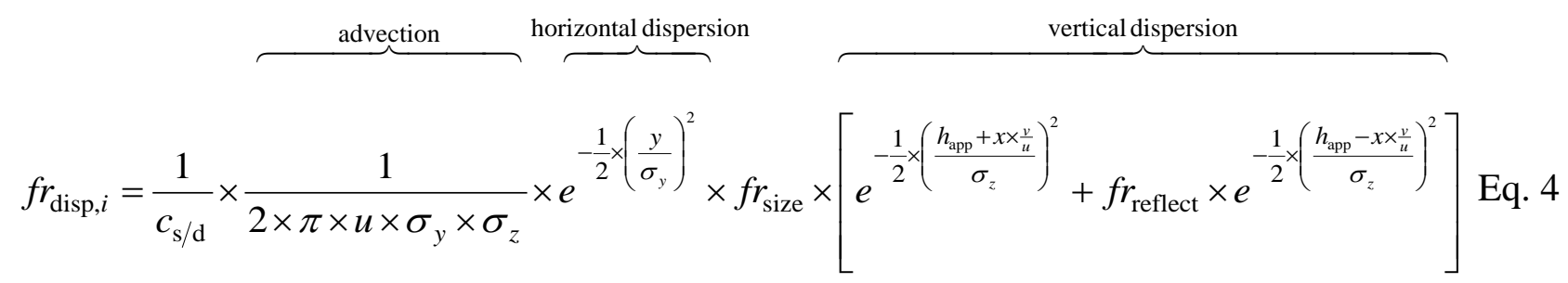
where $f r_{\text {disp }, i}\left[\mathrm{~kg}_{\text {dispersed }} \mathrm{kg}_{\text {drift }}^{-1}\right]$ is the mass fraction of spray drift lost from the field from application in row $i$ and dispersed in downwind direction at distance $x$ within the exposed area, $c_{\mathrm{s} / \mathrm{d}}\left[\mathrm{s} \mathrm{d}^{-1}\right]$ is a conversion factor of seconds per day to correct for the unit of inputs to the plume model, $x[\mathrm{~m}]$ is the downwind distance between field edge and point distance in the exposed bystander area, $y[\mathrm{~m}]$ is the transversal distance away from the center of the plume, $u\left[\mathrm{~m} \mathrm{~s}^{-1}\right]$ is the average wind velocity, $\sigma_{y}$ and $\sigma_{z}[\mathrm{~m}]$ are horizontal and vertical dispersion coefficients of the spray cloud, respectively (US Environmental Protection Agency, 1993), $h_{\mathrm{app}}[\mathrm{m}]$ is the height of spray application which is application technique and crop specific. A default $h_{\text {app }}$ of $0.5 \mathrm{~m}$ above 
Ryberg MW, Mosqueron L, Rosenbaum RK, Fantke P (2018) Addressing bystander exposure to agricultural pesticides in life cycle impact assessment. Chemosphere 197C:541-549. doi:

10.1016/j.chemosphere.2018.01.088

crop canopy for potatoes was used based on Holterman and van de Zande (2003). $v$ [m s ${ }^{-1}$ ] is the settling velocity of spray droplets, $f r_{\text {size }}\left[\mathrm{kg}_{\text {drop-size }} \mathrm{kg}_{\text {total }}^{-1}\right]$ is the mass fraction of the total source strength in the selected drop-size category, and $f r_{\text {reflect }}\left[\mathrm{kg}_{\text {reflected }} \mathrm{kg}_{\text {dispersed }}^{-1}\right]$ is the mass fraction that is reflected (re-emitted) at deposition surfaces. We use a constant prevailing wind direction under the assumption that an average agricultural field is equally surrounded by residential bystander areas in all directions. Thereby, the population-level exposure from a change in wind direction would be the same, which is what we are after in a LCA context where the specific location of a treated field is usually unknown. Further details of the emission and fate calculation are given in Eqs. S1-S10 of the Supplementary material.

\subsubsection{Residential bystander population exposure}

Human exposure via inhalation of residential bystanders living in any pre-defined, exposed area outside a treated agricultural field can be described by an exposure factor:

$$
\mathrm{XF}=\frac{\mathrm{IR} \times n_{\mathrm{pop}}}{V_{\mathrm{air}}} \times c_{\text {exposure }}
$$

where XF $\left[\mathrm{kg}_{\text {inhaled }} \mathrm{d}^{-1}\right.$ per $\left.\mathrm{kg}_{\text {in air }}\right]$ is the bystander inhalation exposure factor within the exposed area, IR $\left[\mathrm{m}_{\text {inhaled }}^{3}\right.$ capita ${ }^{-1} \mathrm{~d}^{-1}$ ] is the average individual human inhalation rate, $n_{\text {pop }}$ [capita] is the number of bystanders living in the exposed area, $V_{\text {air }}\left[\mathrm{m}_{\text {air }}^{3}\right]$ is the volume of air in the exposed area, and $c_{\text {exposure }}$ is a factor correcting for the fact that bystanders during the spray drift period spend part of the time outdoors and part of the time indoors, both within the exposed area (US Environmental Protection Agency, 2011).

Defining the size of the exposed area is essential for modeling exposure of bystanders as it influences the exposed bystander population and related air volume. The width of the exposed area was considered equal to the width of the treated agricultural field ( $\left.w_{\text {field }} ; m\right)$. The field width was 
Ryberg MW, Mosqueron L, Rosenbaum RK, Fantke P (2018) Addressing bystander exposure to agricultural pesticides in life cycle impact assessment. Chemosphere 197C:541-549. doi:

10.1016/j.chemosphere.2018.01.088

based on an estimation of typical European field sizes, which were between 8 to 20 hectares with lengths between 600 and 700 m (European Commision - Joint Research Centre, 2012). This gives a typical field width between 150 and 330 m, from which we defined a default field width of 300 m for the present study. The length of the exposed bystander area outside the field $(l ; \mathrm{m})$ was defined by three archetype distances (i.e. $8 \mathrm{~m}, 50 \mathrm{~m}$ and $100 \mathrm{~m}$ downwind) within which the exposed residents are assumed to be located. The three distances used were based on distances typically evaluated also in risk assessment (Garreyn et al., 2003; Kruijne et al., 2011; Martin et al., 2008) and allow for evaluating exposure within different area sizes.

As the XF is directly proportional to the exposed population size, the number of inhabitants living in the area exposed to pesticide spray drift is an important parameter. The population size in the exposed area was calculated as:

$n_{\text {pop }}=\rho_{\text {pop }} \times w_{\text {field }} \times l$ Eq. 6

Where $\rho_{\text {pop }}$ is the population density in the exposed bystander area [capita $\mathrm{m}_{\text {exposed }}^{-2}$. Specific data on population density near agricultural fields were not available and would likely also show large spatial variability. Therefore, the population density as used in USEtox for the continental scale (i.e. 111 capita per $\mathrm{km}^{2}$ for an average, generic continent (Rosenbaum et al., 2011)) was used as a default value. The sensitivity of the model to this parameter was tested as part of the sensitivity and uncertainty analysis. Further details of the exposure factor calculation and underlying terms are given in Eqs. S11-S13 of the Supplementary material, and information on how we corrected for differences between outdoor and indoor air concentrations are provided in Section S-3 of the Supplementary material.

\subsection{Model evaluation}

\subsubsection{Model sensitivity and uncertainty analysis}


Ryberg MW, Mosqueron L, Rosenbaum RK, Fantke P (2018) Addressing bystander exposure to agricultural pesticides in life cycle impact assessment. Chemosphere 197C:541-549. doi:

10.1016/j.chemosphere.2018.01.088

A Monte Carlo simulation was conducted to determine the probability distribution and variability of the model results and to evaluate the robustness of the model results toward changes in model inputs. Input parameters for the residential bystander model were assigned a probability distribution and probability parameters (see Supplementary materials, Table S8), and the Monte Carlo simulation was run for 10,000 iterations to estimate the probability distribution of the intake fraction, $\mathrm{iF}$, for the residential bystander population at four distance intervals, namely 0 to $100 \mathrm{~m}, 0$ to $8 \mathrm{~m}, 8$ to $50 \mathrm{~m}$, and 50 to $100 \mathrm{~m}$ from the edge of the treated agricultural field.

Based on the Monte Carlo simulation, the squared geometric standard deviation $\left(\mathrm{GSD}^{2}\right)$ of model output was estimated as:

$$
\mathrm{GSD}^{2}=\sqrt{\frac{97.5 \% \text {-ile }}{2.5 \% \text {-ile }}}
$$

The $\mathrm{GSD}^{2}$ describes the variance of the iF uncertainty range across a 95\% confidence interval assuming an ideal lognormal distribution (Fantke et al., 2012b), which is plausible for many parameters involved in calculating environmental processes (Limpert et al., 2001; Ott, 1990).

To demonstrate how to compare uncertainty estimates of spray drift related characterization factors, CFs, for residential bystanders to general population related CFs for impacts on human health obtained with USEtox for far-field environmental exposure pathways, iF and related GSD ${ }^{2}$ values were coupled with effect factors found in the USEtox organic substances database (http://usetox.org) with data for both carcinogenic and non-carcinogenic effects. The uncertainty of the iF was estimated from uncertainty propagation using Taylor series expansion (MacLeod et al., 2002) coupled with the uncertainty of the EFs based on Huijbregts et al. (2005) to give the overall $\mathrm{GSD}^{2}$ of CFs for bystander exposure in the 0 to $100 \mathrm{~m}$ bystander exposure area. Further details on the Monte Carlo simulation are provided in Section S-4 of the Supplementary material.

\subsubsection{Evaluation against measured data}


Ryberg MW, Mosqueron L, Rosenbaum RK, Fantke P (2018) Addressing bystander exposure to agricultural pesticides in life cycle impact assessment. Chemosphere 197C:541-549. doi:

10.1016/j.chemosphere.2018.01.088

Regardless whether model output is or is not sensitive toward changes in model inputs, the accuracy of the model in terms of predicting the "true" value may still be low due to the potential influence of data variability and the relatively small number of model inputs (Huijbregts, 1998). Hence, we also evaluated our bystander exposure model’s predictive ability by comparing predicted average air concentrations (which are the basis for the subsequent inhalation exposure of bystanders) with measured air concentrations based on the relative difference between predicted and measured air concentrations:

Relative difference $\left(C_{\text {predicted }}, C_{\text {measured }}\right)=\frac{\left|C_{\text {predicted }}-C_{\text {measured }}\right|}{C_{\text {measured }}}$ Eq. 8 where $C_{\text {predicted }}\left[\mu \mathrm{g} \mathrm{m}^{-3}\right]$ is the average air concentration over the full considered exposure range of 0 to $100 \mathrm{~m}$ distance from the treated potato field edge estimated with the residential bystander model, and $C_{\text {measured }}\left[\mu \mathrm{g} \mathrm{m}^{-3}\right]$ is the measured air concentration averaged over $100 \mathrm{~m}$ from the field edge within 24 hours after pesticide application based on reported data from a treated potato field in Prince Edward Island, Canada (Garron et al., 2012, 2009). We adapted the measured data to reflect air concentrations that are integrated over distance and time to enable comparison with results from our residential bystander model. Our comparison of model results with measured data was restricted to a very limited set of scenarios, where actual information on field size, application method and meteorological conditions was reported as required input to the residential bystander model. This is in line with recommended data reporting requirements using experimental data inputs to facilitate the parameterization and evaluation of estimation models (Fantke et al., 2016).

\subsubsection{Evaluation against other exposure pathways}

We finally compared our iF estimates for bystanders between 0 and $100 \mathrm{~m}$ from the treated field edge with iFs for other exposure pathways including aggregated inhalation and ingestion 
Ryberg MW, Mosqueron L, Rosenbaum RK, Fantke P (2018) Addressing bystander exposure to agricultural pesticides in life cycle impact assessment. Chemosphere 197C:541-549. doi:

10.1016/j.chemosphere.2018.01.088

exposure mediated via the environment for the general population estimated with the USEtox model (Rosenbaum et al., 2011, 2008), and general population exposure via ingestion of pesticide residues in consumed food crops estimated with the dynamiCROP model (Fantke et al., 2011a, 2011b).

The comparison is based on estimating iFs from USEtox and dynamiCROP and normalizing USEtox iFs to exposure per kg applied to allow comparison of iFs estimated with the residential bystander model and dynamiCROP. Thereby, the pesticide mass in the USEtox air compartment was linked to the mass applied by introducing a generic fraction of the applied mass (spray drift plus volatilization) lost to the air compartment. For pesticide spray applications to potatoes, this fraction was estimated to be $4.85 \%$ with an additional $10 \%$ loss to account for initial volatilization of pesticides (Fantke and Jolliet, 2016). For dynamiCROP, the exposed population was estimated from the total harvested annual potato yield of $1.6 \mathrm{~kg} \mathrm{~m}^{-2}$ (Juraske et al., 2011) multiplied with the considered field area from Table 1 and divided by the annual amount of potatoes consumed per capita of $32 \mathrm{~kg} \mathrm{capita}^{-1}$ (FAO, 2013). The comparison was done for carbofuran (insecticide), chlorothalonil (fungicide).

\section{Results}

\subsection{Bystander exposure and comparison with measured data}

Figure 2 shows estimated average air concentrations integrated over all spray rows within residential bystander areas over different distance ranges from the edge of a treated agricultural field. It is apparent that concentrations are substantially higher close to the field edge and that concentrations decrease rapidly after about $10 \mathrm{~m}$ from the field. The difference in average air concentrations between the 0 (agricultural field edge) to $8 \mathrm{~m}$ bystander range and the 50 to $100 \mathrm{~m}$ bystander range is about four orders of magnitude. Indeed, the average air concentration between 0 and $100 \mathrm{~m}$ was found to be dominated by the concentration within the initial 0 to $8 \mathrm{~m}$ range. 
Ryberg MW, Mosqueron L, Rosenbaum RK, Fantke P (2018) Addressing bystander exposure to agricultural pesticides in life cycle impact assessment. Chemosphere 197C:541-549. doi:

10.1016/j.chemosphere.2018.01.088

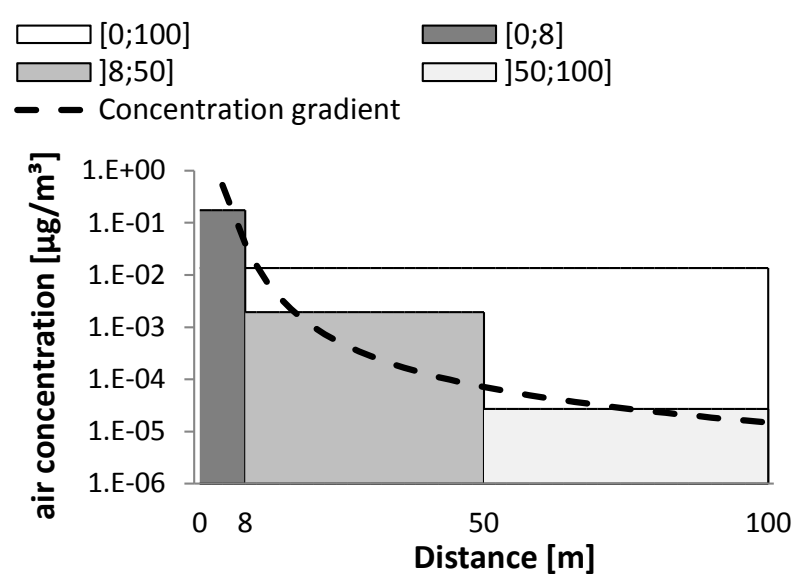

Figure 2 Gradient in outdoor air concentration integrated over all spray rows from 0 to $100 \mathrm{~m}$ range as a result of $1 \mathrm{~kg}$ of pesticide, with chlorothalonil as active ingredient, applied to a generic agricultural field using a conventional boom sprayer. The figure also shows the average outdoor air concentration integrated over all spray rows within four distinct ranges over distances from the treated agricultural field edge covering potentially exposed bystander areas.

Table 1 shows estimated iFs based on parameters reported together with air concentration measurements (Garron et al., 2012, 2009). Across application scenarios of different pesticides and different bystander exposure distance ranges, iFs differ by less than one order of magnitude within the 0 to $8 \mathrm{~m}$ and 0 to $100 \mathrm{~m}$, distance ranges (where the latter range is dominated by the 0 to $8 \mathrm{~m}$ range), while the difference in iFs between scenarios was substantially larger with about four orders of magnitude within the 8 to $50 \mathrm{~m}$ and 50 to $100 \mathrm{~m}$ distance ranges. Table 1 also shows how model predictions for pesticide air concentrations match with reported field measurements. The relative difference between the predicted (i.e. modeled) average air concentration between 0 and $100 \mathrm{~m}$ exposed bystander range and the reported average air concentration between 0 and 100 m measured over the first 24 hours after pesticide application to potato fields ranges between 0.07 and 1.47 . We observe a notable difference between measured and predicted air concentrations. However, the difference is considered acceptable for providing a realistic indication of the time and space integrated air concentration. This is also true when taking into account the inherent variability in 
Ryberg MW, Mosqueron L, Rosenbaum RK, Fantke P (2018) Addressing bystander exposure to agricultural pesticides in life cycle impact assessment. Chemosphere 197C:541-549. doi:

10.1016/j.chemosphere.2018.01.088

measured spray drift concentrations and the general uncertainty related to describing air

concentrations as a function of wind speed, temperature, relative humidity, etc. (see Supplementary

material, Section S2). Therefore, the modeling approach is considered of suitable accuracy for

providing a representative estimate of pesticide concentration in air from spray drift as a result of

pesticide application to potato fields.

Table 1 Predicted bystander population intake fractions (iF) for different pesticide application scenarios and different exposure distance ranges from the treated agricultural field, predicted $\left(\mathrm{C}_{\text {predicted }}\right)$ and measured $\left(\mathrm{C}_{\text {measured }}\right)$ air concentrations between 0 and $100 \mathrm{~m}$ and their relative difference, and main model inputs, namely wind speed $(u)$, relative humidity $(r h)$, air temperature ( $\left.T_{\text {air }}\right)$, mass of pesticide applied $\left(m_{\text {app }}\right)$, treated field area $\left(A_{\text {field }}\right)$, field length along the prevailing wind direction $\left(L_{\text {field }}\right)$, application duration $\left(t_{\text {app }}\right)$, and population density $\left(\rho_{\text {pop }}\right)$. All scenarios represent a separate field trial test, where pesticides have been applied and measured at different distances from the field edge and at different times over the course of one day.

\begin{tabular}{|c|c|c|c|c|c|c|c|c|c|c|c|c|c|c|c|c|}
\hline \multicolumn{2}{|r|}{ Scenario } & \multicolumn{8}{|c|}{ Model inputs } & \multicolumn{4}{|c|}{ iF $\left[\mathrm{kg}_{\text {inhaled }} \mathrm{kg}^{-1}{ }_{\text {applied }}\right]$} & \multirow{2}{*}{\begin{tabular}{|c|}
$\begin{array}{c}C_{\text {predicted }} \\
{\left[\mu \mathrm{g} \mathrm{m}^{-3}\right]}\end{array}$ \\
$\begin{array}{c}0 \text { to } \\
100 \mathrm{~m}\end{array}$
\end{tabular}} & \multirow{2}{*}{\begin{tabular}{|c}
$\begin{array}{c}C_{\text {measured }}{ }^{(3)} \\
{\left[\mu \mathrm{g} \mathrm{m}^{-3}\right]}\end{array}$ \\
$\begin{array}{c}0 \text { to } 100 \\
\mathrm{~m}\end{array}$
\end{tabular}} & \multirow{2}{*}{$\begin{array}{l}\text { Relative } \\
\text { difference }\end{array}$} \\
\hline \# & Pesticide & $\begin{array}{c}u \\
{\left[\mathrm{~m} \mathrm{~s}^{-1}\right]}\end{array}$ & $\begin{array}{c}r h \\
{[\%]}\end{array}$ & $\begin{array}{c}T_{\text {air }} \\
{\left[{ }^{\circ} \mathrm{C}\right]}\end{array}$ & $\begin{array}{l}m_{\text {app }} \\
{[\mathrm{kg}]}\end{array}$ & $\begin{array}{l}\text { Afield } \\
\text { [ha] }\end{array}$ & $\begin{array}{l}\text { Lfield } \\
{[\mathrm{m}]}\end{array}$ & $\begin{array}{l}\text { tapp } \\
\text { [hr] }\end{array}$ & $\begin{array}{c}\rho_{\mathrm{pop}} \\
\text { [capita } \\
\mathrm{m}^{-2} \text { ] }\end{array}$ & 0 to $8 \mathrm{~m}$ & 8 to $50 \mathrm{~m}$ & $\begin{array}{c}50 \text { to } 100 \\
\mathrm{~m}\end{array}$ & 0 to $100 \mathrm{~m}$ & & & \\
\hline $1^{(1)}$ & Chlorothalonil & 3.5 & 79 & 18.4 & 12.1 & 0.1 & 336 & 1.2 & $1.11 \times 10^{-4}$ & $5.9 \times 10^{-10}$ & $7.6 \times 10^{-11}$ & $2.7 \times 10^{-12}$ & $1 \times 10^{-10}$ & 0.22 & 0.11 & 1.05 \\
\hline $2^{(1)}$ & Chlorothalonil & 2.1 & 69 & 19.9 & 12.1 & 10.1 & 333 & 0.6 & $1.11 \times 10^{-4}$ & $8.6 \times 10^{-10}$ & $6.5 \times 10^{-12}$ & $8.8 \times 10^{-14}$ & $7.9 \times 10^{-10}$ & 0.29 & 0.34 & 0.14 \\
\hline $3^{(1)}$ & Chlorothalonil & 1.6 & 78 & 20.9 & 4.8 & 4 & 133 & 0.4 & $1.11 \times 10^{-4}$ & $2.5 \times 10^{-9}$ & $1.6 \times 10^{-13}$ & $7.3 \times 10^{-16}$ & $2.3 \times 10^{-9}$ & 0.33 & 0.36 & 0.07 \\
\hline $4^{(1)}$ & Chlorothalonil & 2.1 & 73 & 26.3 & 4.8 & 4.0 & 133 & 0.4 & $1.11 \times 10^{-4}$ & $1.9 \times 10^{-9}$ & $1.3 \times 10^{-11}$ & $1.6 \times 10^{-13}$ & $1.8 \times 10^{-9}$ & 0.26 & 0.57 & 0.55 \\
\hline $5^{(2)}$ & Carbofuran & 3.0 & 83 & 16.3 & 6.4 & 12.1 & 270 & 0.6 & $1.11 \times 10^{-4}$ & $1.1 \times 10^{-9}$ & $4.9 \times 10^{-11}$ & $1.2 \times 10^{-12}$ & $1.0 \times 10^{-9}$ & 0.13 & 0.08 & 0.61 \\
\hline 6(2) & Methamidophos & 2.7 & 68 & 15.6 & 8.7 & 8.1 & 403 & 0.5 & $1.11 \times 10^{-4}$ & $3.4 \times 10^{-10}$ & $1.5 \times 10^{-11}$ & $3.5 \times 10^{-13}$ & $3.3 \times 10^{-10}$ & 0.13 & 0.66 & 0.80 \\
\hline $7^{(2)}$ & Mancozeb & 4.0 & 94 & 18.6 & 21.8 & 12.1 & 403 & 0.6 & $1.11 \times 10^{-4}$ & $3.2 \times 10^{-10}$ & $6.3 \times 10^{-11}$ & $2.7 \times 10^{-12}$ & $3.5 \times 10^{-10}$ & 0.23 & 0.09 & 1.47 \\
\hline
\end{tabular}

${ }^{1}$ Data from Garron et al. (2012); ${ }^{2}$ Data from Garron et al. (2009); ${ }^{3}$ Experimental data were averaged from 0 to 24 hr and from 0 to $100 \mathrm{~m}$ to get results that were comparable with outputs from the residential bystander model.

\subsection{Model sensitivity and uncertainty results}

Based on the Monte Carlo simulation, Figure 3 shows the variability of bystander population iF (i.e. intake fraction of all bystanders considered within the exposed area next to the treated 
Ryberg MW, Mosqueron L, Rosenbaum RK, Fantke P (2018) Addressing bystander exposure to agricultural pesticides in life cycle impact assessment. Chemosphere 197C:541-549. doi:

10.1016/j.chemosphere.2018.01.088

agricultural field) and individual bystander $\mathrm{iF}^{\text {person }}$ (i.e. intake fraction of a single bystander person determined by dividing the exposure factor by the number of bystanders living in the considered exposed area; see Eq. 5). The variability in iF values for the 0 to $100 \mathrm{~m}$ and 0 to $8 \mathrm{~m}$ distance ranges is very similar, because iF for the 0 to $100 \mathrm{~m}$ range is again dominated by $\mathrm{iF}$ for the 0 to $8 \mathrm{~m}$ range. The 95\% confidence interval is about one order of magnitude for both total bystander iF and individual bystander $\mathrm{iF}^{\text {person }}$ in the 0 to $100 \mathrm{~m}$ and 0 to $8 \mathrm{~m}$ distance ranges, which indicates relatively little variability. The parameters contributing most to variability are wind speed, application duration and individual inhalation rate for $\mathrm{iF}^{\mathrm{person}}$, while these parameters together with bystander population density are dominating for total bystander iF. For the 8 to $50 \mathrm{~m}$ and 50 to 100 m distance ranges, the 95\% confidence interval spans over three orders of magnitude and the parameters contributing most to variability were wind speed, relative humidity and application duration for $\mathrm{iF}^{\text {person }}$, while these parameters together with population density are dominating for total bystander iF. Details of the sensitivity of modeled air concentrations as output of the fate model toward the aforementioned input parameters are provided in Section S-4 of the Supplementary material. In general, little difference in variability was found at the exposure results level between $\mathrm{iF}$ and $\mathrm{iF}^{\mathrm{person}}$, which is primarily due to the relatively low population density within the exposed bystander area, where e.g. the total population living within the total 0 to $100 \mathrm{~m}$ distance range is on average only 3.37 persons. Hence, the varying population within the bystander area does not differ much from the $\mathrm{iF}^{\mathrm{person}}$ where only a single bystander is considered. 
Ryberg MW, Mosqueron L, Rosenbaum RK, Fantke P (2018) Addressing bystander exposure to agricultural pesticides in life cycle impact assessment. Chemosphere 197C:541-549. doi:

10.1016/j.chemosphere.2018.01.088

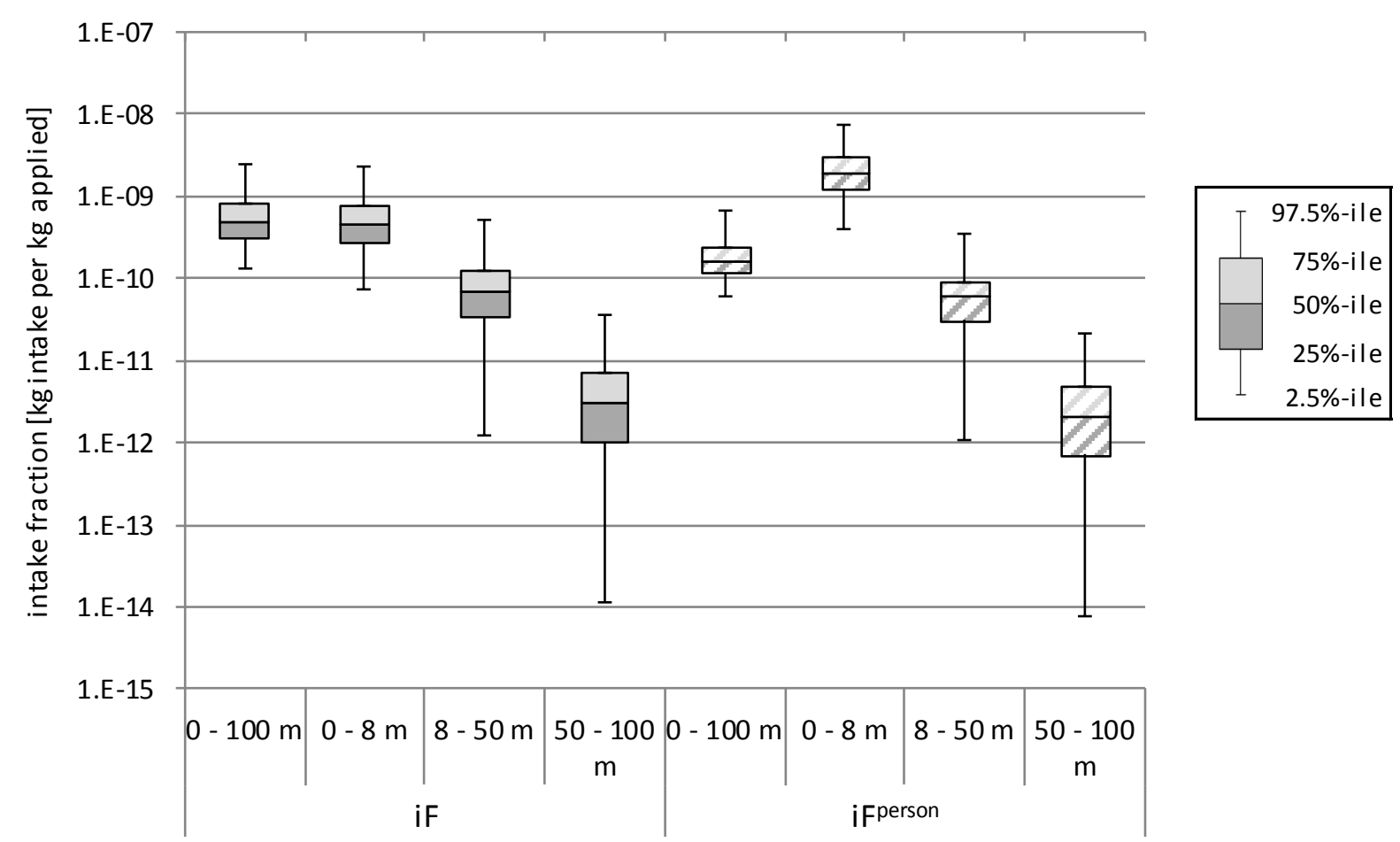

Figure 3 Box plots showing intake fraction ranges across Monte Carlo simulations for four bystander exposure distance ranges from the field edge, highlighting the difference in exposure at different distances to the treated field and also evaluating exposure per capita compared to exposure of the entire considered bystander population.

Overall, our bystander exposure model does not appear highly sensitive to changes in model inputs as the $\mathrm{GSD}^{2}$ for $\mathrm{iF}_{[0-100 \mathrm{~m}]}$ was 4.27 and the corresponding lower and upper $95 \%$ confidence interval limits are respectively $1.3 \times 10^{-10}$ and $2.4 \times 10^{-9} \mathrm{~kg}$ inhaled by the bystander population per kg applied pesticide. This means that between 0.13 and 24 ppb (parts per billion) of applied pesticides are inhaled by bystanders with $95 \%$ certainty in our scenarios. After coupling the uncertainty of the bystander intake fraction in the range 0 to $100 \mathrm{~m}, \mathrm{iF}_{[0-100 \mathrm{~m}]}$, with the uncertainty of the effect factor, EF, linking exposure to disease risk, the GSD² of the corresponding characterization factors, $\mathrm{CF}_{[0-100 \mathrm{~m}]}$, were 78.7 and 192.4 for non-carcinogenic and carcinogenic health effects, respectively. Based on this scenario, the $\mathrm{GSD}^{2}$ for $\mathrm{CF}_{[0-100 \mathrm{~m}]}$ lies within the 
Ryberg MW, Mosqueron L, Rosenbaum RK, Fantke P (2018) Addressing bystander exposure to agricultural pesticides in life cycle impact assessment. Chemosphere 197C:541-549. doi:

10.1016/j.chemosphere.2018.01.088

uncertainty for other CFs for impacts on human health ranging from 77 to 2189 depending on the emission compartment and exposure pathway considered (Rosenbaum et al., 2008). However, the highest contribution to the uncertainty of our bystander exposure related CFs is not associated with our estimated intake fractions, but with the extrapolated human effect factor, especially for the widely varying non-cancer effects, which is consistent with other studies (Fantke et al., 2012a; Huijbregts et al., 2005; Rosenbaum et al., 2008).

\subsection{Comparison of different exposure pathways}

Figure 4 shows the results of the comparison between $\mathrm{iF}_{[0-100 \mathrm{~m}]}$ for bystanders and the iFs predicted by USEtox for environmentally mediated general population exposure aggregating inhalation and ingestion, and by dynamiCROP for general population ingestion exposure to residues in harvested food crops. The differences in iFs between bystander exposure, environmentally mediated population exposure and population exposure to crop residues (Figure 4) show that crop residue ingestion and environmentally mediated exposure dominates total exposure from pesticides applied to agricultural fields, while bystander exposure only contributes by about $0.1 \%$ to the total iF (sum over all exposed populations and exposures associated with the same application scenario).

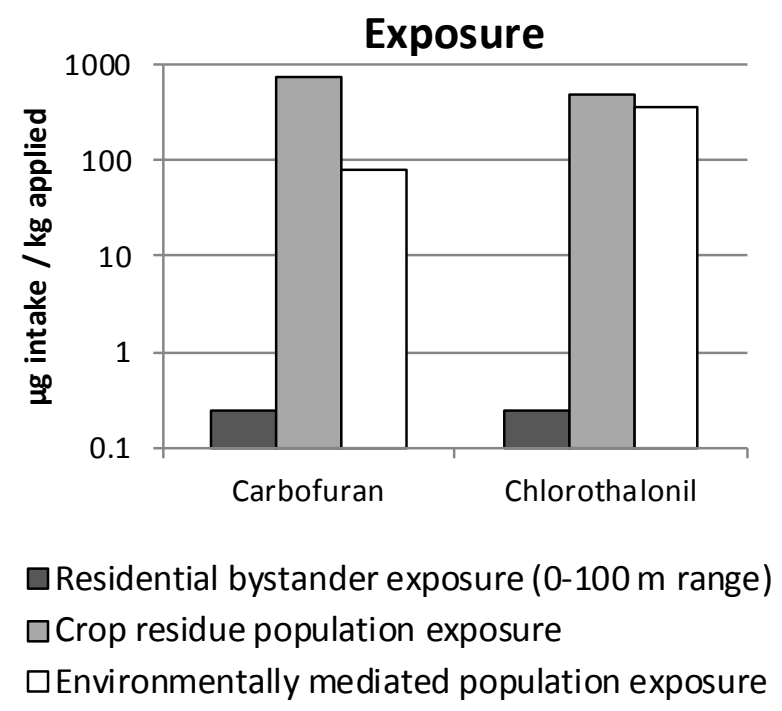


Ryberg MW, Mosqueron L, Rosenbaum RK, Fantke P (2018) Addressing bystander exposure to agricultural pesticides in life cycle impact assessment. Chemosphere 197C:541-549. doi:

10.1016/j.chemosphere.2018.01.088

Figure 4 Intake fractions for total exposed population (all considered bystanders for bystander exposure, all exposed consumers for crop residue exposure, and total population for environmentally mediated exposure) per kg of pesticide applied to agricultural fields.

The question is, however, whether this kind of direct comparison between iF representing different population sizes is meaningful. Indeed, bystander exposure was found to dominate together with exposure via ingestion of crop residues aggregated per capita (i.e. individual) intake fractions, while environmentally mediated general population exposure was found to have almost no contribution to aggregated individual intake fractions (Figure 5).

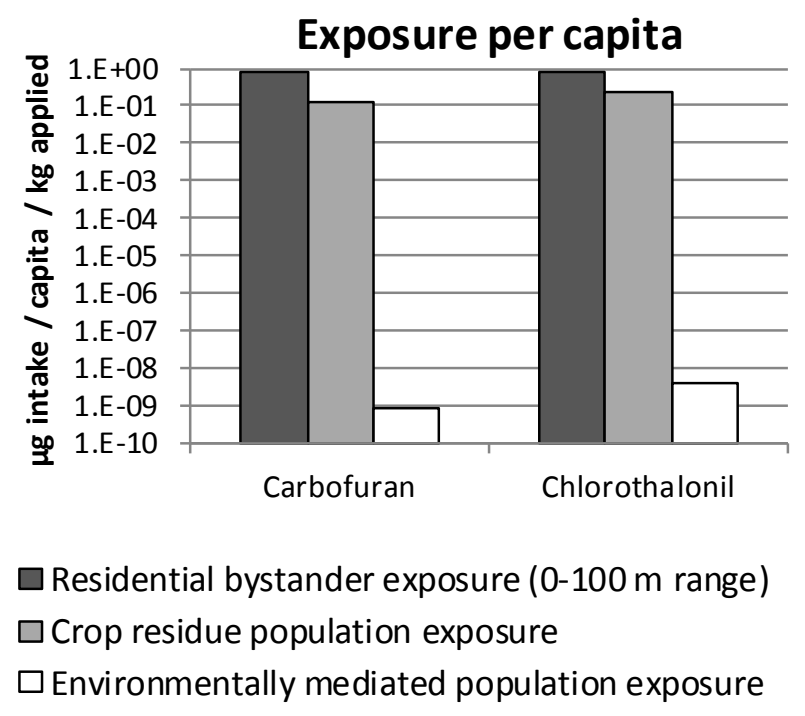

Figure 5 Individual (i.e. per capita) intake fractions per kg of pesticide applied to agricultural fields.

\section{Discussion}

\subsection{Model framework and performance}

The developed residential bystander model allows for predicting intake fractions for different exposure ranges as a function of the distance from the field of application. Related 
Ryberg MW, Mosqueron L, Rosenbaum RK, Fantke P (2018) Addressing bystander exposure to agricultural pesticides in life cycle impact assessment. Chemosphere 197C:541-549. doi:

10.1016/j.chemosphere.2018.01.088

characterization factors can be estimated by multiplication of these bystander exposure results with effect factors for the assessed pesticides. It is, per default, recommended for LCA practitioners to apply results for the 0 to $100 \mathrm{~m}$ distance to the field edge range, because this range includes the full residential bystander population potentially exposed to pesticide spray drift fractions and, thereby, gives the most comprehensive indication of related bystander exposure. However, the fact that exposure of bystanders decreases substantially after about $8 \mathrm{~m}$ distance from the considered field edge underlines the benefit of spray buffer zones around agricultural fields which can substantially reduce exposure of bystanders to spray drift (de Snoo and de Wit, 1998). Such a difference in agricultural practice is of interest from an LCA perspective, particularly in the agrifood sector, and our model allows this to be captured in LCA results.

The model was only compared to measurements for ground field crops (potatoes). The model predictions were generally in good agreement with field measurements for pesticide air concentrations, especially in relation to natural variability of pesticide application and spray drift together with general uncertainty in measurements of spray drift. This shows that our bystander exposure model provides a realistic indication for the exposure of bystanders to pesticides during and after application to agricultural fields. However, further testing of the model against measurements for other application such as in orchards or vineyards is required to increase the validity and applicability of the model. The comparison of our bystander exposure estimates with estimates of exposure from crop residues and environmentally mediated emissions shows that bystander exposure does contribute to overall pesticide population intake, but that population intake is generally not dominated by spray drift related exposure of bystanders, which is mainly due to the small fraction of the general population that is considered to be residential bystanders living in the close vicinity to agricultural fields.

Dividing the fate calculation part of the bystander model framework into an emission fraction quantification component and an environmental fate quantification component as part of 
Ryberg MW, Mosqueron L, Rosenbaum RK, Fantke P (2018) Addressing bystander exposure to agricultural pesticides in life cycle impact assessment. Chemosphere 197C:541-549. doi:

10.1016/j.chemosphere.2018.01.088

the impact assessment is practical as it allows for using individual parts of the model for more specific assessments, e.g. for impact assessment in modelling exposure to humans from pesticide spray drift and for inventory modelling in estimating loss of pesticide from agricultural fields. As for human exposure, the model currently includes inhalation-related pathways, while dermal exposure from deposition of spray drift on bystanders is not included due to lack of relevant data regarding deposition area, dermal uptake and related human effects information.

Moreover, for evaluating agricultural product systems in a life cycle perspective, the inclusion of an inventory part (i.e. pesticide loss from fields after application) coupled with an LCIA model that includes the fate of the spray drift outside the field is an advantage, because information about specific pesticide losses from the field (e.g. spray drift, run-off, volatilization) are often unknown while information about the mass of pesticide applied to the field are usually well known (Rosenbaum et al., 2015). Hence, our bystander exposure model provides a consistent framework linking known inventory data (mass applied) via emissions to environmental fate and exposure for bystander populations. For application and use in LCA studies, iFs estimated using the residential bystander model can be coupled with pesticide-specific EFs (as shown in Eq. 1) to estimate pesticide-specific CFs for off-field spray drift from agricultural pesticide application. CFs thereby represent potential human toxicity impacts per kg pesticide applied to the field. This aligns well with recommendations that life cycle inventories should report the mass applied of each active ingredient (Rosenbaum et al., 2015) in order to consistently cover all pathways relevant for pesticides. Moreover, iFs for off-field spray drift can be integrated into existing LCIA toxicity characterization models, but would have to be extended to cover many more existing pesticides. For instance, our pathway can be included in USEtox by adapting the intake fraction matrix. Such integration would then facilitate a consistent and more comprehensive assessment of human exposure to toxic substances in practice. 
Ryberg MW, Mosqueron L, Rosenbaum RK, Fantke P (2018) Addressing bystander exposure to agricultural pesticides in life cycle impact assessment. Chemosphere 197C:541-549. doi:

10.1016/j.chemosphere.2018.01.088

\subsection{Application by LCA practitioners}

Our bystander exposure calculations are generally based on generic input data for cases where specific information on the application scenario is lacking, but can be modified to quantify site- and application method-specific characterization results in cases where the LCA practitioner has detailed knowledge about underlying environmental conditions and pesticide application. It was found that the most influential parameters are bystander population density, wind speed, application duration and individual inhalation rate. Statistics on average wind speed and application duration are available or can be measured on site, while inhalation rate is traditionally well studied with sound measurements of human inhalation rates, e.g. from the US Environmental Protection Agency (2011). To ensure a robust quantification of bystander exposure, specific data on the population density or the number of bystanders in the exposed area should be retrieved. These data will essentially be specific to each area (or field).

The model currently includes spray drift curves for ground spraying of, e.g. potatoes, cereals, and for spraying of fruit trees (see Supplementary material, Table S3) and can quantify spray drift associated with these crops. Other application methods, such as aerial application and hand-operated sprayers, are currently not included due to a lack of information regarding the associated losses from spray drift. It is recommended for assessments of specific cases to obtain spray drift curves that are as representative as possible to their case in order to get the most precise results. This is, for instance, the case for assessments of specific crops and application techniques, but also for assessments under different environmental and climatic conditions, which may affect spray drift, e.g. as described in Kasiotis et al. (2014).

\subsection{Individual exposure compared to population exposure}

The results showed that per capita exposure was higher for bystanders compared to per capita exposure for pathways associated with environmentally mediated emissions or crop residues 
Ryberg MW, Mosqueron L, Rosenbaum RK, Fantke P (2018) Addressing bystander exposure to agricultural pesticides in life cycle impact assessment. Chemosphere 197C:541-549. doi:

10.1016/j.chemosphere.2018.01.088

(Figure 5), highlighting the significance of the population size considered to be exposed.

Essentially, this means that the sub-population qualifying as bystanders may be exposed by more than twice the pesticide dose than the general population receives on average, depending on the pesticide. In LCIA practice, however, this will currently not be captured since exposures are only calculated on the total population level, so that we observe a "dilution" of those higher exposures as shown in Figure 4. So far, toxicity LCIA models only consider exposure pathways affecting the entire population (i.e. inhalation and ingestion of chemicals via food, including pesticide residues, and general environmental exposure). As soon as a particular sub-population, e.g. bystanders or workers, with a potentially much higher exposure than the general population is included in the assessment, the impacts (or exposures) cannot simply be summed up anymore, because that will render the higher impacts on the sub-population (few people with high exposure/effects) invisible compared to the impacts on the general population (billions of people with very low exposure/effects) and will also not capture potentially relevant differences in the dose-response for low versus high exposure levels. This illustrates a known limitation to LCIA in not highlighting the most exposed or vulnerable populations but instead focusing on highlighting (and comparing) total population-level exposure.

This accentuates the need for harmonizing the assessment of different population sizes in LCA as only reporting aggregated population-level intake fractions will fail to reveal the large variability in the actual exposure of different populations. The lack of focus on exposure of specific population groups might lead to unfavorable decision-making, because exposure exceeding tolerable doses for specific populations may be overlooked if diluted in population-level exposure results. This dilemma does not only occur for exposure to spray drift but for all types of exposure that are predominantly targeting specific population groups (e.g. specific occupational or consumer exposure settings). Hence, further research is required to allow for an adequate consideration of 
Ryberg MW, Mosqueron L, Rosenbaum RK, Fantke P (2018) Addressing bystander exposure to agricultural pesticides in life cycle impact assessment. Chemosphere 197C:541-549. doi:

10.1016/j.chemosphere.2018.01.088

sub-populations with higher exposures, which will also open the door to integration of occupational and consumer exposure into the LCIA toxicity characterization.

\section{Conclusions}

We presented a framework for assessing residential bystander exposure to pesticide applications to agricultural fields which closes a gap in the exposure assessment included in LCA studies where agricultural pesticides play a role. The inclusion of bystander exposure aids decisionmaking based on LCA because previously unavailable insights about exposure of bystanders can now be taken into account in LCA. The model showed a reasonable predictive capability in comparison with field crops (potatoes). Our model currently provides a proof-of-concept that spray drift can be included in LCIA, and the model can be used by LCA practitioners to address exposure to initial pesticide spray drift. However, the model will have to be further adapted and validated against data for additional crop types and other application techniques, such as aerial and handoperated spraying, should be included.

It was found that exposure of bystanders is limited relative to total exposure of populations from ingestion of pesticide residues in crops, but that the magnitude taken in by bystanders can be substantially larger than the intake of populations not living in the proximity to agricultural fields. Hence, more focus on the most exposed populations as part of LCA could be beneficial to provide a more comprehensive basis for decision-making where not only total population exposure, but also exposure of differentiated population groups is taken into account.

Our bystander exposure model is available free of charge upon request from the authors.

\section{Notes}

The authors have no competing interests to declare. 
Ryberg MW, Mosqueron L, Rosenbaum RK, Fantke P (2018) Addressing bystander exposure to agricultural pesticides in life cycle impact assessment. Chemosphere 197C:541-549. doi:

10.1016/j.chemosphere.2018.01.088

\section{Acknowledgements}

This work was supported by the Marie Curie projects Tox-Train (GA No. 285286) and Quan-Tox (GA No. 631910) funded by the European Commission under the Seventh Framework Programme and by the OLCA-Pest project financially supported by ADEME (GA No. 17-03C0025). We thank Cédric Wannaz and Christine Garron for valuable input to the mathematical framework and for providing experimental air concentration data, respectively.

\section{Supplementary data}

A full mathematical model description, specific details on parameters used for sensitivity and uncertainty analysis, details on the estimation of indoor-outdoor pesticide concentration ratios, and a list of reviewed spray drift models are provided in the Supplementary material. 
Ryberg MW, Mosqueron L, Rosenbaum RK, Fantke P (2018) Addressing bystander exposure to agricultural pesticides in life cycle impact assessment. Chemosphere 197C:541-549. doi:

10.1016/j.chemosphere.2018.01.088

\section{References}

Arya, S., 2003. A review of the theoretical bases of short-range atmospheric dispersion and air quality models. Proc. Indian Natl. Sci. Acad. 69A, 709-724.

Craig, I.., 2004. The GDS model—a rapid computational technique for the calculation of aircraft spray drift buffer distances. Comput. Electron. Agric. 43, 235-250.

Crettaz, P., Pennington, D., Rhomberg, L., Brand, K., Jolliet, O., 2002. Assessing Human Health Response in Life Cycle Assessment Using ED10s and DALYs: Part 1-Cancer Effects. Risk Anal. 22, 931-946.

de Snoo, G.R., de Wit, P.J., 1998. Buffer Zones for Reducing Pesticide Drift to Ditches and Risks to Aquatic Organisms. Ecotoxicol. Environ. Saf. 41, 112-118.

Dijkman, T.J., Birkved, M., Hauschild, M.Z., 2012. PestLCI 2.0: a second generation model for estimating emissions of pesticides from arable land in LCA. Int. J. Life Cycle Assess. 17, 973986.

European Commision - Joint Research Centre, 2012. Agriculture Field Parameters on NUTS regions for Wind erosion research [WWW Document]. URL

http://eusoils.jrc.ec.europa.eu/library/themes/erosion/winderosion/data.html

Fantke, P., Arnot, J.A., Doucette, W.J., 2016. Improving plant bioaccumulation science through consistent reporting of experimental data. J. Environ. Manage.

Fantke, P., Charles, R., de Alencastro, L.F., Friedrich, R., Jolliet, O., 2011a. Plant uptake of pesticides and human health: dynamic modeling of residues in wheat and ingestion intake. Chemosphere 85, 1639-47.

Fantke, P., Friedrich, R., Jolliet, O., 2012a. Health impact and damage cost assessment of pesticides in Europe. Environ. Int. 49, 9-17.

Fantke, P., Jolliet, O., 2016. Life cycle human health impacts of 875 pesticides. Int. J. Life Cycle Assess. 21, 722-733.

Fantke, P., Juraske, R., Antón, A., Friedrich, R., Jolliet, O., 2011b. Dynamic multicrop model to characterize impacts of pesticides in food. Environ. Sci. Technol. 45, 8842-9.

Fantke, P., Wieland, P., Juraske, R., Shaddick, G., Itoiz, E.S., Friedrich, R., Jolliet, O., 2012b. Parameterization models for pesticide exposure via crop consumption. Environ. Sci. Technol. 46, 12864-72.

FAO, 2013. FAOSTAT Food Balance Sheets. Food and Agriculture Organization of the United Nations [WWW Document]. URL http://faostat3.fao.org/faostat-gateway/go/to/home/E

Ganzelmeier, H., Rautmann, D., Spangenberg, R., Streloke, M., Herrmann, M., Wenzelburger, H.J., Walter, H.F., 1995. Studies on the spray drift of plant protection products: results of a test program carried out throughout the Federal Republic of Germany. Blackwell, Berlin.

Garreyn, F., Vagenende, B., Steurbaut, W., 2003. Harmonised environmental Indicators for pesticide risk - "Occupational” indicators - Operator, worker and bystander. SPE - CT - 2003 501997.

Garron, C.A., Davis, K.C., Ernst, W.R., 2009. Near-field air concentrations of pesticides in potato agriculture in Prince Edward Island. Pest Manag. Sci. 65, 688-96.

Garron, C., Ernst, B., Julien, G., Losier, R., Davis, K., 2012. Concentrations and environmental risk of chlorothalonil in air near potato fields in Prince Edward Island, Canada. Pest Manag. Sci. 
Ryberg MW, Mosqueron L, Rosenbaum RK, Fantke P (2018) Addressing bystander exposure to agricultural pesticides in life cycle impact assessment. Chemosphere 197C:541-549. doi:

10.1016/j.chemosphere.2018.01.088

68, 92-100.

Holterman, H.J., van de Zande, J.C., 2003. IMAG Drift Calculator v1.1 User Manual.

Huijbregts, M.A.J., 1998. Application of Uncertainty and Variability in LCA Part I : A General Framework for the Analysis of Uncertainty and Variability in Life Cycle Assessment. Int. J. Life Cycle Assess. 3, 273-280.

Huijbregts, M.A.J., Rombouts, L.J.A., Ragas, A.M.J., van de Meent, D., 2005. HumanToxicological Effect and Damage Factors of Carcinogenic and Noncarcinogenic Chemicals for Life Cycle Impact Assessment Human-Toxicological Effect and Damage Factors of Carcinogenic and Noncarcinogenic Chemicals for Life Cycle Impact Assessment. Integr. Environ. Assess. Manag. 1, 181-244.

Jolliet, O., Rosenbaum, R., Chapman, P.M., McKone, T., Margni, M., Scheringer, M., Van Straalen, N., Wania, F., 2006. Establishing a Framework for Life Cycle Toxicity Assessment. Findings of the Lausanne Review Workshop. Int. J. Life Cycle Assess. 11, 209-212.

Juraske, R., Mosquera Vivas, C.S., Erazo Velásquez, A., García Santos, G., Berdugo Moreno, M.B., Diaz Gomez, J., Binder, C.R., Hellweg, S., Guerrero Dallos, J.A., 2011. Pesticide uptake in potatoes: Model and field experiments. Environ. Sci. Technol. 45, 651-657.

Kasiotis, K.M., Glass, C.R., Tsakirakis, A.N., Machera, K., 2014. Spray drift reduction under Southern European conditions: A pilot study in the Ecopest Project in Greece. Sci. Total Environ. 479-480, 132-137.

Kennedy, M.C., Butler Ellis, M.C., Miller, P.C.H., 2012. BREAM: A probabilistic Bystander and Resident Exposure Assessment Model of spray drift from an agricultural boom sprayer. Comput. Electron. Agric. 88, 63-71.

Kruijne, R., Deneer, J., Lahr, J., Vlaming, J., 2011. HAIR2010 Documentation; Calculating risk indicators related to agricultural use of pesticides within the European Union. Wageningen, Alterra, Alterra-report 2113.1.

Lebeau, F., Verstraete, A., Stainier, C., Destain, M.-F., 2011. RTDrift: A real time model for estimating spray drift from ground applications. Comput. Electron. Agric. 77, 161-174.

Limpert, E., Stahel, W. a., Abbt, M., 2001. Log-normal Distributions across the Sciences: Keys and Clues. Bioscience 51, 341.

MacLeod, M., Fraser, A.J., Mackay, D., 2002. Evaluating and expressing the propagation of uncertainty in chemical fate and bioaccumulation models. Environ. Toxicol. Chem. 21, 700-9.

Martin, S., Westphal, D., Erdtmann-Vourliotis, M., Dechet, F., Schulze-Rosario, C., Stauber, F., Wicke, H., Chester, G., 2008. Guidance for Exposure and Risk Evaluation for Bystanders and Residents exposed to Plant Protection Products during and after Application. J. für Verbraucherschutz und Leb. 3, 272-281.

Matthews, G., Hamey, P., 2003. Exposure of bystanders to pesticides. Pestic. Outlook 14, $210-212$.

Miller, P., Hadfield, D., 1989. A simulation model of the spray drift from hydraulic nozzles. J. Agric. Eng. Res. 42, 135-147.

Ott, W.R., 1990. A Physical Explanation of the Lognormality of Pollutant Concentrations. J. Air Waste Manage. Assoc. 40, 1378-1383.

Rautmann, D., Streloke, M., Winkler, R., 2001. New basic drift values in the authorisation procedure of pesticides, in: Workshop on Risk Assessment and Risk Mitigation Measures in the Context of Authorisation of Pesticides (WORMM). Mitt. Biol. Bundesanst. LandForstwirtsch. Berlin-Dahlem, Heft 381, Berlin. 
Ryberg MW, Mosqueron L, Rosenbaum RK, Fantke P (2018) Addressing bystander exposure to agricultural pesticides in life cycle impact assessment. Chemosphere 197C:541-549. doi:

Reiss, R., Griffin, J., 2006. A probabilistic model for acute bystander exposure and risk assessment for soil fumigants. Atmos. Environ. 40, 3548-3560.

Rosenbaum, R.K., Anton, A., Bengoa, X., Bjørn, A., Brain, R., Bulle, C., Cosme, N., Dijkman, T.J., Fantke, P., Felix, M., Geoghegan, T.S., Gottesbüren, B., Hammer, C., Humbert, S., Jolliet, O., Juraske, R., Lewis, F., Maxime, D., Nemecek, T., Payet, J., Räsänen, K., Roux, P., Schau, E.M., Sourisseau, S., van Zelm, R., von Streit, B., Wallman, M., 2015. The Glasgow consensus on the delineation between pesticide emission inventory and impact assessment for LCA. Int. J. Life Cycle Assess. 20, 765-776.

Rosenbaum, R.K., Bachmann, T.M., Gold, L.S., Huijbregts, M.A.J., Jolliet, O., Juraske, R., Koehler, A., Larsen, H.F., MacLeod, M., Margni, M., McKone, T.E., Payet, J., Schuhmacher, M., van de Meent, D., Hauschild, M.Z., 2008. USEtox-the UNEP-SETAC toxicity model: recommended characterisation factors for human toxicity and freshwater ecotoxicity in life cycle impact assessment. Int. J. Life Cycle Assess. 13, 532-546.

Rosenbaum, R.K., Huijbregts, M.A.J., Henderson, A.D., Margni, M., McKone, T.E., Meent, D., Hauschild, M.Z., Shaked, S., Li, D.S., Gold, L.S., Jolliet, O., 2011. USEtox human exposure and toxicity factors for comparative assessment of toxic emissions in life cycle analysis: sensitivity to key chemical properties. Int. J. Life Cycle Assess. 16, 710-727.

Salyani, M., Cromwell, R., 1992. Spray drift from ground and aerial applications. Trans. ASAE 35.

Teske, M., Bowers, J., Rafferty, J., Barry, J., 1993. FSCBG : An Aerial Spray Dispersion Model. Environ. Toxicol. Chem. 12, 453-464.

Teske, M.E., Bird, S.L., Esterly, D.M., Curbishley, T.B., Ray, S.L., Perry, S.G., 2002. AgDRIFT: a model for estimating near-field spray drift from aerial applications. Environ. Toxicol. Chem. 21, 659-71.

US Environmental Protection Agency, 1993. Selection Criteria for mathematical Models used in Exposure Assessments : Atmospheric Dispersion Models. Washington, D.C.

US Environmental Protection Agency, 2011. Exposure Factors Handbook : 2011 ed. Washington D.C.

van de Zande, J.C., Wenneker, M., Michielsen, J.M.G.P., 2010. Risk estimation of bystander and residential exposure from orchard spraying based on measured spray drift data. Asp. Appl. Biol. 99, 149-156. 